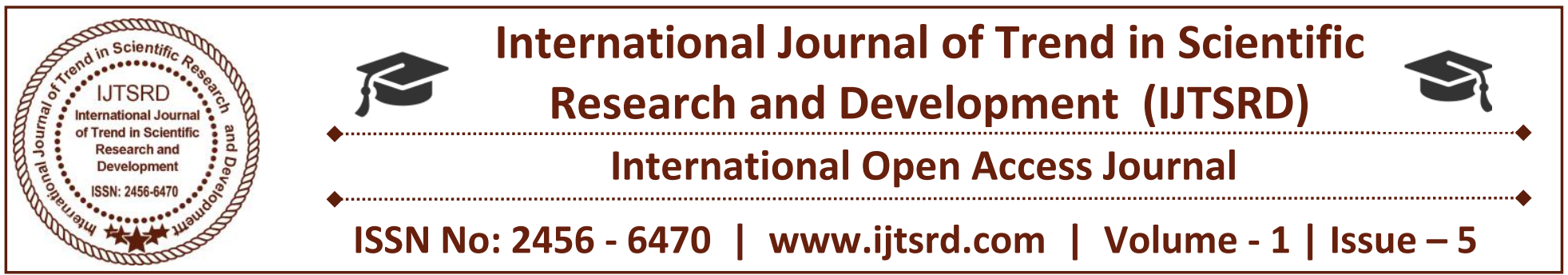

\title{
Effectiveness of Diabetic Risk Reduction Package on Knowledge, among Prediabetic Employees in Selected Instiututions, Thiruvallur District
}

\author{
Mrs. Aswathi. K.V \\ Phd scholar, Omayal Achi College of Nursing, \\ Chennai, Tamil Nadu, India
}

\author{
Dr. S. Vijayalakshmi \\ Principal, Vignesh College of Nursing, \\ Thiruvanamalai, Tamil Nadu, India
}

\begin{abstract}
\section{Background:}

Diabetes is considered as a multi system disorder, whose prevalence is globally increasing and is considered as a global health change of $21^{\text {st }}$ century. World Health Organization (WHO) estimates the adults having diabetes in 2014 was 422 million with obesity considered as a major contributing factor. Prediabetes is defined as impaired fasting Glucose or impaired glucose tolerance with fasting blood glucose 100-125mg/dl. Prediabetes is considered as a distinct entity under the classification of ICD-10 with diagnostic code R73-09. It's a reversible condition projecting the last window opportunity against impeding diabetes. Diabetes can be considerably overcome through simple and safe measures to promote health and prevent development of Diabetes from prediabetes.
\end{abstract}

\section{Aim:}

The study aimed at assessing the effectiveness of Diabetes Risk Reduction package on knowledge among prediabetic employees.

\section{Methods:}

Quantitative research approach with quasi experimental design was used. A total of 178 prediabetic employees aged between 20-60 years, who could understand English and were teaching in the selected schools formed the samples, with 90 and 88 prediabetic employees each from twenty selected schools of Thiruvallur District, formed the experimental and control group. Enumerative sampling technique was used to select the samples. Data was collected using the Questionnaire prepared by the investigator.

\section{Results:}

Statistical analysis of the background variables revealed homogeneity between the experimental and control group in the pre-test. . The mean gained knowledge score for the experimental group was 8.87 and for control group it was only 0.44 which showed that the experimental group had improved to a great extent. There was increase in post test knowledge score for all the components and it was statistically significant at $\mathrm{P}<0.001$ level.

Mild positive correlation was identified between the knowledge and life style.

\section{Conclusion:}

The results indicated that the intervention tool brought significant improvement in knowledge on prediabetes which proved the effectiveness of DRRP. It was found to be simple and practicable for maintaining the healthy life and preventing the progression to diabetes by gain of adequate knowledge on prediabetes.

\section{Recommendation:}

Adequate knowledge on prediabetes can help the employees to prevent its progression to diabetes in future. 


\section{INTRODUCTION}

Health is the central happiness to every human being. Good health results in overall performance and efficiency. Over past few years our life style has been changed and we have become the prey for various lifestyle diseases including Diabetes, hypertension and cancer. Diabetes is considered as a multi system disorder, whose prevalence is globally increasing ${ }^{1}$ and is considered as a global health change of $21^{\text {st }}$ century ${ }^{2}$. Diabetes is usually preceded by a condition known as Prediabetes.It is condition where the individuals has higher than normal levels of blood sugar but not high enough to be diagnosed as diabetes. It's a metabolic state relating to insulin resistance, characterized by impaired fasting glucose (IFG) or impaired glucose tolerance (IGT). Prediabetes is an intermediate state between normal regulation of blood glucose and hyperglycemia ${ }^{3}$. Prediabetes is considered as a distinct entity under the classification of ICD-10 with diagnostic code R73-09. It's a reversible condition projecting the last window opportunity against impeding diabetes. Adopting healthy life style with regards to activity and dietary practices has shown beneficial effects in halting the progression to type 2 Diabetes $^{4}$. The novelty of the present study is that it was performed among the employee's (school teachers) as good health results in productive employment. Younger generation are becoming the prey for life style diseases due to overburden of studies, fast foods and use of mobiles and gadgets instead of active play .Teachers can bring a desirable change in the behaviour of an individual and having an awareness in prediabetes and its risk factors can implement those life style measures among them and in the upcoming generation.

\section{MATERIALS AND METHODS}

The study was carried out among prediabetic employees in selected schools of Thiruvalur District. Adult employees (20-60) years were screened for prediabetes and whose FBS $100-125 \mathrm{mg} / \mathrm{dl}$ and IDRS $>30$ were termed as prediabetes was included for the study. Totally 723 teachers were screened and 178 were prediabetes divided into experimental (90) and control group (88).They were informed about the study and written informed consent was obtained. The participants completed the questionnaire on knowledge with regard to prediabetes and its prevention to diabetes. There was a statistical significance difference in knowledge between the two groups.

\section{INTERVENTIONS}

The knowledge interventions in present study was implemented through DRRP which included Information Education and communication on needed life style practices provided by the investigator. The intervention group received the DRRP after the pretest. The same group was evaluated for the post test after 7 days. The control group was just assessed with pretest and after a week with post test.

\section{RESULTS}

The base line characteristics were assessed majority were females. Figure 1 showed the overall pre and post test level of knowledge score among the prediabetic employees in experimental and control group. The analysis revealed that in the pretest none of the samples had adequate knowledge; $46(51.1 \%)$, $44(48.9 \%)$ of experimental with mean value of 11.83 and $46(52.3 \%), 42(47.7 \%)$ of control with mean value 12.11 had moderate and inadequate knowledge respectively which revealed the similarity of samples in the pretest. 
Fig 1.Frequency, percentage and comparison of life style variable of experiment and control group in pre test and post test

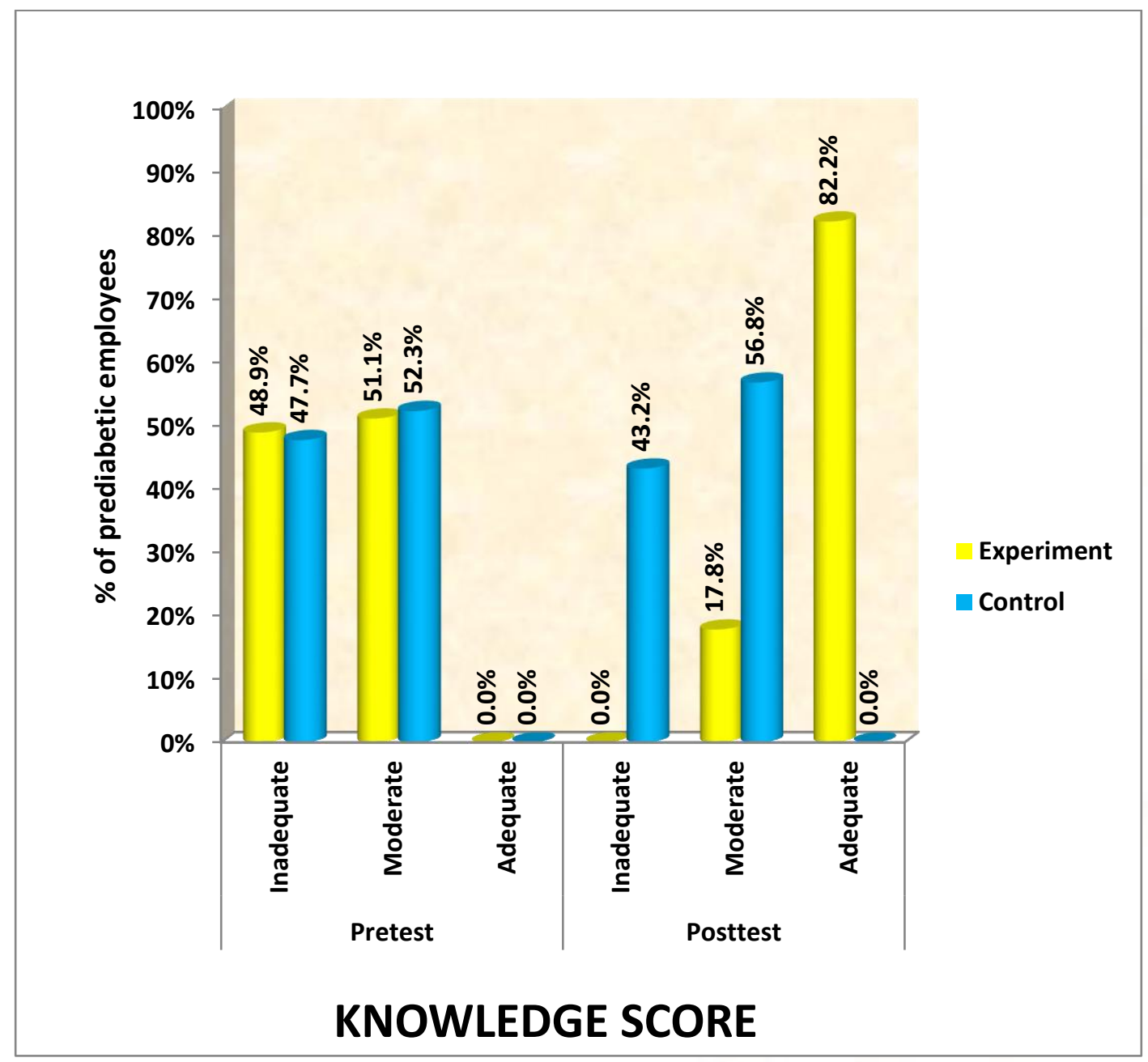

After implementation of DRRP in Table 1 the post test result revealed that majority $74(82.2 \%), 16(17.8 \%)$ of prediabetic employees in the experimental group with mean value of 20.70 had moderate and adequate knowledge but none of them had adequate knowledge in the control group. The mean gained knowledge score for the experimental group was 8.87 and for control group it was only 0.44 which showed that the experimental group had improved to a great extent. There was increase in knowledge for all the components and it was statistically significant at $\mathrm{P}<0.001$ level. 
Fig2: Box-Plot graph compares the pretest, and posttest knowledge score between experiment and control group prediabetic employees

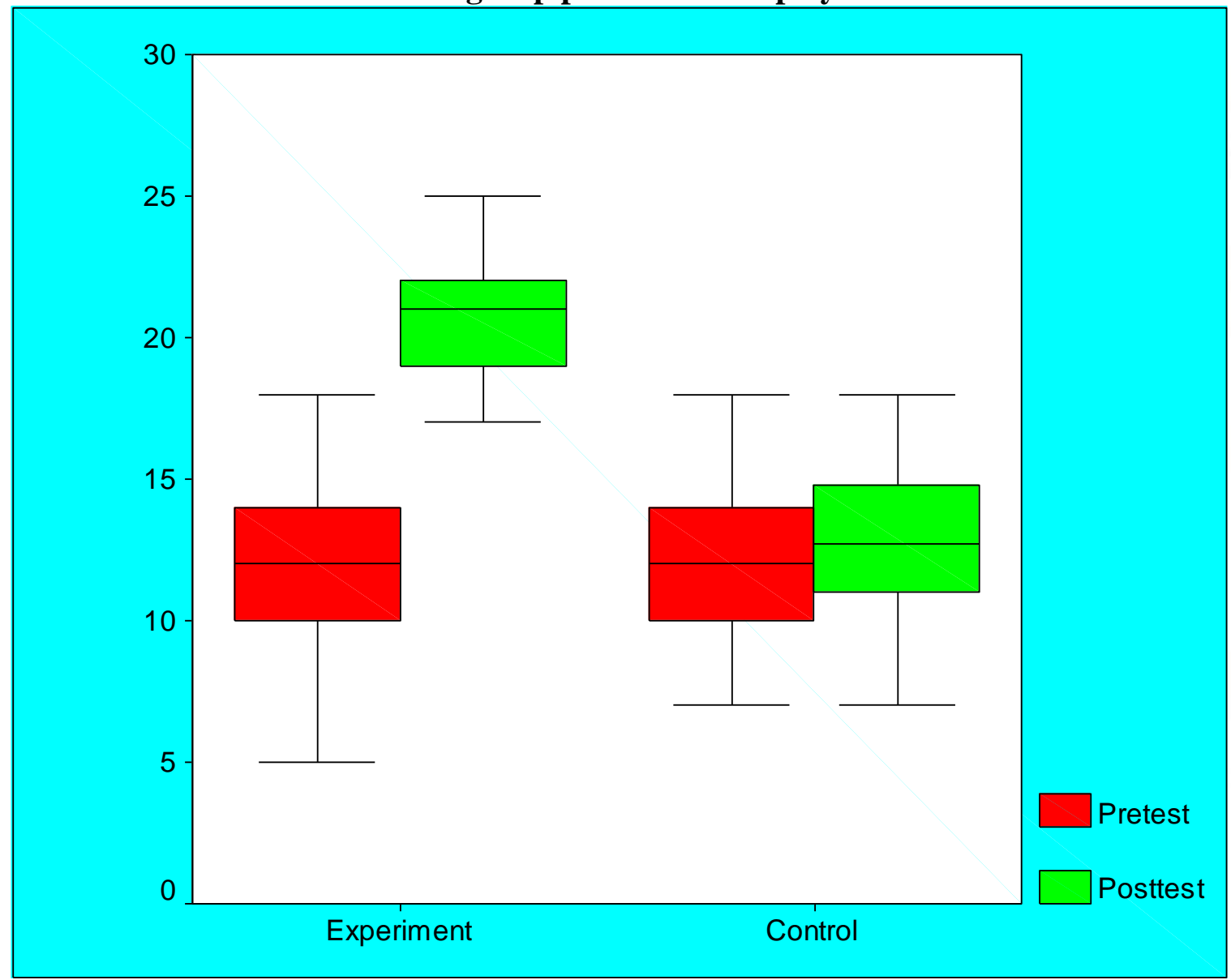

Table 1: Effectiveness of diabetic risk reduction package on knowledge among prediabetic employees in experimental and control group

\begin{tabular}{|c|c|c|c|c|c|}
\hline \multirow{2}{*}{ Group } & \multicolumn{2}{|c|}{ Pretest } & \multicolumn{2}{|c|}{ Posttest } & \multirow{2}{*}{$\begin{array}{c}\text { Student's } \\
\text { Dependent t-test }\end{array}$} \\
\hline & Mean & SD & Mean & SD & \\
\hline $\begin{array}{l}\text { Experimental } \\
n=90\end{array}$ & 11.83 & 3.01 & 20.70 & 1.89 & $\begin{array}{c}\mathrm{t}=30.02 \\
\mathrm{P}=0.001 * * *\end{array}$ \\
\hline $\begin{array}{l}\text { Control } \\
n=88\end{array}$ & 12.11 & 2.46 & 12.55 & 2.50 & $\mathrm{t}=1.79, \mathrm{P}=0.08$ \\
\hline $\begin{array}{l}\text { Unpaired } \\
\text { t- test }\end{array}$ & \multicolumn{2}{|c|}{$\mathrm{t}=0.66, \mathrm{P}=0.51$} & \multicolumn{2}{|c|}{$\mathrm{t}=24.54, \mathrm{P}=0.001 * * *$} & \\
\hline
\end{tabular}

The comparison between experimental and control group which was done by independent test that showed no statistical significance found in pre-test but high statistical significance was found in post test at $\mathrm{p}<0.001$.
The above findings revealed that the mean difference of the variables were high for the experimental group comparing to the control group which proved that the DRRP was highly effective in bringing the adequate knowledge on prediabetes and this awareness can help 
International Journal of Trend in Scientific Research and Development (IJTSRD) ISSN: 2456-6470

in the lifestyle practices thereby preventing or delaying diabetes in future.

\section{CONCLUSION}

It has become the need of the hour that we seriously have to think out how many of the life threatening and devastating diseases and its burden can be prevented by simple modification in our lifestyle practices. One side extensive researches and clinical trials are being carried out for inventing modernised high tech equipments, high potent drugs and advanced technology for the diagnostic and therapeutic field in order to reduce the burden caused by NCDs. On the other side we fail to prevent these by simple modifications of dietary, physical activity and life style habits which would make a great difference in our life. We fail to observe our own behaviour and activities which results in serious health problems. It has become essential for everybody to know about the health behaviour to lead a healthy life. The DRRP helps the individual to know about the prediabetes, develop healthy practices to prevent development of diabetes by gaining adequate knowledge on prediabetes.

\section{ABBREVIATIONS}

FBS -Fasting Blood Sugar; IDRS-Indian Diabetic Risk Score, DRRP-Diabetic Risk Reduction Package

\section{REFERENCES}

1) Joshi SR, Aravind SR. Diabetes in India and Southeast Asia. InDiabetes Mellitus in Developing Countries and Underserved Communities 2017 (pp. 85-100). Springer International Publishing.

2) Mudey AB, Wagh V. Incidence of pre-diabetes and its risk factors in rural Maharashtra, India. International Journal of Bioassays. 2015 Oct 1;4(10):4379-81.

3) Ramachandran A, Snehalatha C. Current scenario of diabetes in India. Journal of diabetes. 2009 Mar $1 ; 1(1): 18-28$.

4) Midha T, Krishna V, Shukla R, Katiyar P, Kaur S, Martolia DS, Pandey U, Rao YK. Correlation between hypertension and hyperglycemia among young adults in India. World Journal of Clinical Cases: WJCC. 2015 Feb 16;3(2):171.

5) Midha T, Krishna V, Shukla R, Katiyar P, Kaur S, Martolia DS, Pandey U, Rao YK. Correlation between hypertension and hyperglycemia among young adults in India. World Journal of Clinical Cases: WJCC. 2015 Feb 16;3(2):171.

6) Mohan V, Sandeep S, Deepa R, Shah B, Varghese C. Epidemiology of type 2 diabetes: Indian scenario. Indian Journal of medical Research. 2007 Mar 1;125(3):217 